\title{
O ENSINO DO PLEONASMO NA ESCOLA BÁSICA: por uma abordagem reflexiva $e$ interacionista no tratamento da figura de linguagem e do vício de linguagem em aulas de Língua Portuguesa
}

The teaching of pleonasm in the basic school: by a reflexive and interactionist approach in the treatment of the figure of language and of language addiction in classes of Portuguese Language

\author{
Emanuelly Nascimento Gomes ${ }^{1}$ \\ lanara Wanderley Dias Leite dos Santos ${ }^{2}$ \\ Francisco Renato Lima ${ }^{3}$
}

RESUMO: Este artigo apresenta uma reflexão acerca do ensino do pleonasmo na escola básica, partindo das concepções de linguagem e de gramática, postuladas por Travaglia (2009), sobretudo. Parte-se do fato de que, historicamente, prevaleceu no ensino, uma concepção de gramática normativa e tradicional, que fragmenta a língua, enquanto utilização social e também, um modelo gramatical ideal, considerando o antagonismo do pleonasmo como figura de sintaxe ou linguagem e sua classificação como vício de linguagem. Metodologicamente, partimos de uma pesquisa exploratória, pela análise bibliográfica, à luz de autores como: Abaurre; Abaurre; Pontara (2010), Bakhtin (2009), Bechara (2006), Cegalla (2008), Geraldi (2012), Koch (2012), Martelotta (2013), Soares (1998), entre outros. Busca-se contemplar as relações entre os conceitos de figura de linguagem e vício de linguagem e como eles podem convergir em alguns aspectos. No caso do pleonasmo vicioso, que, por ser considerado defeituoso por utilizar repetições desnecessárias nas construções, vai de encontro com o conceito de pleonasmo como figura de linguagem, visto que, nesse, também são utilizadas repetições, que não são tidas como desnecessárias, por serem consideradas um recurso estilístico utilizado para intensificar uma ideia, que é muito usual na literatura, também conhecido como pleonasmo literário, enquanto o pleonasmo vicioso, que mais é comumente utilizado na oralidade não possui essa mesma denominação, no entanto, em última análise, eles possuem a mesma finalidade de evidenciar algo. Diante disso, refletimos sobre a necessidade de adotarmos modelos didáticos, partindo de uma concepção interacionista de linguagem, que pode trazer implicações pedagógicas que melhorem processo de ensino e aprendizagem.

\footnotetext{
${ }^{1}$ Graduanda em Letras - Português e Francês (UFPI). E-mail: emanuelly.gms@gmail.com

${ }^{2}$ Graduanda em Letras - Português e Francês (UFPI). E-mail: ianarawds@gmail.com

${ }^{3}$ Mestre em Letras - Estudos da Linguagem (UFPI). Professor Substituto (Auxiliar Nível - I) da Universidade Federal do Piauí, lotado no Departamento de Métodos e Técnicas de Ensino (DMTE). Coordenador de disciplinas do Centro de Educação Aberta e a Distância (CEAD/UFPI). E-mail: fcorenatolima@hotmail.com
} 
Palavras-chave: Ensino de Língua Portuguesa. Pleonasmo. Figura de linguagem; Vício de linguagem. Prática pedagógica.

ABSTRACT: This article presents a reflection about the teaching of pleonasm in the basic school, starting from the conceptions of language and grammar postulated by Travaglia (2009), above all. It begins with the fact that, historically, a conception of normative and traditional grammar, which fragments language as a social use and also an ideal grammatical model, has prevailed in teaching, considering the antagonism of pleonasm as a figure of syntax or language and classification as language addiction. Methodologically, we start from an exploratory research, by the bibliographical analysis, in the light of authors like: Abaurre; Abaurre; (2010), Bakhtin (2009), Bechara (2006), Cegalla (2008), Geraldi (2012), Koch (2012), Martelotta (2013) and Soares (1998). It is sought to contemplate the relations between the concepts of figure of language and addiction of language and how they can converge in some aspects. In the case of vicious pleonasm, which, because it is considered defective by using unnecessary repetitions in the constructions, goes against the concept of pleonasm as a figure of language, since in this, repetitions are also used, which are not considered as unnecessary, for are considered a stylistic resource used to intensify an idea, which is very usual in literature, also known as literary pleonasm, while the vicious pleonasm, which is more commonly used in orality does not have this same denomination, however, in the final analysis, they have the same purpose of evidencing something. In light of this, we reflect on the need to adopt didactic models, starting from an interactionist conception of language, which can have pedagogical implications that improve teaching and learning process.

Keywords: Teaching of Portuguese Language. Pleonasm. Figure of speech; Addiction of language. Pedagogical practice.

\section{CONSIDERAÇÕES INICIAIS}

A gramatica normativa, por seu caráter prescritivo, que busca padronização da língua, tem sido alvo de inúmeras críticas por parte de linguistas que, interessados na descrição e explicação dos atos de fala, construídos nas situações de uso, criticam a gramática como um catálogo de regras para um escrito exemplar, na qual, tudo o que não é previsto é excluído como desvio. Incorporado na gramática normativa, o pleonasmo, que é um recurso linguístico utilizado para fins de enfatizar algo já dito ou uma ideia proposta, será o tema analisado no presente 
estudo, a partir de uma reflexão relativa ao antagonismo do pleonasmo como figura de sintaxe, ou linguagem e sua classificação como vício de linguagem.

Pretende-se analisar as descrições do pleonasmo como figura de linguagem segundo alguns autores da gramática prescritiva (BECHARA, 2006; CEGALLA, 2008), partir de alguns exemplos e correlacionar o seu uso, baseado no ponto de vista da gramática normativa, que fragmenta a língua enquanto utilização social e enquanto modelo gramatical ideal, originando dessa ideia, uma noção de 'certo' e 'errado'. Concernente a esse modelo, temos o conceito de vício de linguagem, que corresponde a construções que não vão de encontro com as normas da gramática, do 'bem falar e escrever', tidos como defeituosos, que permanecem à margem da língua padrão, por serem classificados como termos de ignorância. No caso do pleonasmo vicioso, ou redundância, diz-se que há uma repetição desnecessária, enquanto como figura é representada para dar realce a uma ideia.

No decorrer deste estudo serão analisadas as relações entre esses conceitos e como eles podem convergir em alguns aspectos, baseado na análise das concepções de linguagem (GERALDI, 2012; KOCH, 2012; SOARES, 1998; TRAVAGLIA, 2009) e nas abordagens de ensino referente a elas ${ }^{4}$. No caso de observação do pleonasmo vicioso, considerado defeituoso por utilizar repetições desnecessárias nas construções, vai ao encontro do conceito de pleonasmo como figura de linguagem, visto que, nesse, também são utilizadas repetições que não são tidas como desnecessárias por serem consideradas um recurso estilístico utilizado para intensificar uma ideia, que é muito usual na literatura (ALI, 1964; BECHARA, 1969), também conhecido como pleonasmo literário, enquanto o pleonasmo vicioso, que mais é comumente utilizado na oralidade, não possui essa mesma denominação, no entanto, será mostrado em exemplos como, em última análise, o

\footnotetext{
${ }^{4}$ A esse respeito, vale mencionar a comunicação oral: "Tendências pedagógicas, opção político-ideológica e concepções de linguagem: das correlações, tomadas de partido e aproximações didático-metodológica no ensino de Língua Portuguesa", apresentada no II Congresso Nacional de Variação/Diversidade Linguística e Letramentos (II CONVALLE), realizado na Universidade Federal do Piauí (UFPI), de 4 a 6 de setembro de 2018. No estudo, o autor "considera-se que, cada uma das três concepções de linguagem, [...] assumem uma estreita relação com as tendências pedagógicas que orientam o proceder didático em sala de aula identificadas [...]". Amparando-se nas contribuições dos estudos da Educação (Pedagogia) e Letras (Linguística), o autor conclui, apontando para a necessidade de uma associação entre "a terceira concepção de linguagem - como forma de interação - a uma Pedagogia Progressista, realizável pelas Tendências Libertadora, Libertária e "Críticosocial dos conteúdos", uma vez que, em ambas, encontra-se a valorização do sujeito no processo de construção do conhecimento" (LIMA, 2018, p. 01).
} 
fato de que eles possuem a mesma finalidade, a de evidenciar algo e como o ensino pode ser adequado a uma abordagem interacionista para amoldar essa questão.

Objetiva-se refletir quanto aos conceitos prescritos pela gramática sobre o pleonasmo e exemplificar, através de algumas situações, como aqueles são prescindíveis para conceituar esse recurso. Cumpre, assim, por meio da utilização de uma concepção funcionalista de linguagem, aplicada as situações de uso da língua, repensarmos na gramática de cunho reflexivo, para que possamos examinar se as concepções referentes ao pleonasmo são realmente necessárias para o estudo desse recurso. Para isso, a metodologia utilizada no artigo será pautada no método bibliográfico e parcialmente descritivo.

\section{A GRAMÁtICA NO ENSINO DE LÍNGUA PORTUGUESA: ENDEREÇANDO OLHARES COMPARATIVOS PARA AS ABORDAGENS NORMATIVA E SOCIONTERACIONISTA DA LÍNGUA/LINGUAGEM}

O ensino de língua materna se organiza com alguns objetivos, que dizem respeito, particularmente, ao desenvolvimento de competências e habilidades de uso da língua. Isto é, na capacidade de utilizar a língua em situações comunicativas, sendo elas textuais, gramaticais, ou linguísticas, a fim de que usuário possa ampliar sua desenvoltura e adequá-la a diferentes eventos de comunicação. Com base nisso, podemos refletir acerca do ensino da língua tendo em vista as concepções da linguagem, que ainda conforme Travaglia (2009, p. 21) "é tão importante quanto a postura que se tem relativamente à educação".

Essa visão é compartilhada por outros estudiosos. Dentre eles, Geraldi (2012, p. 40), inclusive citado por Travaglia ${ }^{5}$ quando destaca que ser professor e dar aulas de Língua Portuguesa implica em tomada de decisões ideológicas, pois "toda e qualquer metodologia de ensino articula uma opção política - que envolve uma teoria de compreensão e interpretação da realidade". No mesmo entendimento, Antunes (2003, p. 36), aponta que a prática do professor é resultado das teorias que estuda, visto que "os princípios são o fundamento em que o professor vai apoiar-se para criar suas opções de trabalho".

\footnotetext{
${ }^{5}$ Importante de se ressaltar, pois o clássico texto de Geraldi é de 1985, e serviu inclusive, como suporte para as reflexões de Travaglia, que publicou seu livro em 1995.
}

Cadernos Cajuína, V. 4, N. 1, 2019, p.173 - 193.

ISSN: 2448-0916 
A princípio, a primeira concepção de linguagem, concebe-a como expressão do pensamento, que ao contemplarmos dessa maneira, podemos compreender que as pessoas que não conseguem se expressar bem não pensam, pois, segundo essa concepção, a linguagem se constrói no interior da mente sendo sua expressão a explanação dessa. Portanto, a capacidade do ser humano de organizar seus pensamentos de forma lógica está diretamente atrelada a como ele se expressa. Sendo assim, para que o usuário se expresse bem, há uma organização pautada em regras que devem ser seguidas (GERALDI, 2012; TRAVAGLIA, 2009).

A concepção de linguagem como expressão de pensamento foi o alicerce para os estudos linguísticos que demarcaram a gramática normativa. Também conhecida como gramática tradicional, tem origem nos filósofos gregos, que constituíram a ideia da tradição gramatical regulada, baseado em seus estudos da relação entre linguagem, o pensamento e a realidade, o que segundo Martelotta (2013) veio de Aristóteles, a ideia de que existe uma forte relação de linguagem e lógica, o que fora anteriormente comentado a respeito da organização mental da concepção que a rege.

Pelo seu caráter normativo, a gramática tradicional é fortemente criticada por estudiosos da língua (ANTUNES, 2007; BAGNO, 2007; BRITTO, 1997; FARACO, 2006; FRANCHI et al., 2006; LUFT, 2008; NEVES, 2010; POSSENTI, 1996; dentre outros); e linguistas modernos ${ }^{6}$, pois ela propõe restrições à utilização da língua em situações comunicativas, e, consequentemente, resulta em um ensino de baixo desempenho linguístico, visto que os elementos linguísticos se tornam limitados à regras de correção, quando há um grande número de diversas construções fora dos padrões gramaticais, pois segundo Travaglia (2009), a gramática normativa é mais uma espécie de lei que regula o uso da língua em sociedade.

\footnotetext{
${ }^{6}$ A esse respeito de obras de linguistas brasileiros que caminham nesse sentido, cita-se: a Gramática de usos do português, de Maria Helena de Moura Neves, publicada em (2000), e que permaneceu praticamente como única com essa proposta teórica; mas, no final da década, surgem outros trabalhos, a exemplo: a Gramática Houaiss da Língua Portuguesa (AZEREDO, 2008), Gramática do brasileiro (FERRAREZI JR.; TELES, 2008), Gramática do português brasileiro (PERINI, 2010), Nova gramática do português brasileiro (CASTILHO, 2010), Gramática pedagógica do português brasileiro (BAGNO, 2011), Pequena gramática do português brasileiro (CASTILHO; ELIAS, 2012), Gramática de bolso do português brasileiro (BAGNO, 2013), e, mais recentemente, em 2018, novamente, Maria Helena de Moura Neves, com A gramática do português revelada em textos.

Para maior aprofundamento sobre essa questão, ver o trabalho de Farias (2014).
}

Cadernos Cajuína, V. 4, N. 1, 2019, p.173- 193.

ISSN: 2448-0916 
Embora constituída há milênios, a concepção de linguagem ligada a gramática normativa, ainda é o ensino vigente nas escolas. Em razão de suas características regulamentárias e descrições formais da língua, o ensino pautado nessa prescrição não favorece que os alunos desenvolvam suas habilidades linguísticas, devido seu caráter prescritivo e meramente metalinguístico, ou seja, utiliza de um meio de descrição linguística para se objetivar o domínio apenas da variedade padrão da língua. Conforme Geraldi (2012), atenta-se mais a questões gramaticais, e problemas ortográficos os quais são os mais observados nas atividades orais e escritas.

Além disso, essa gramática se constitui seguindo alguns elementos que delimitam o ensino, tais como: seu caráter elitista ou aristocrático, a respeito da valorização do uso da língua pela classe de prestígio, em detrimento da linguagem popular; do mesmo modo, carrega um cunho político, por condenar estrangeirismos. E. principalmente comunicacional, dado que, relacionada à concepção de "expressão do pensamento", o ensino prescritivo exige clareza e concisão na interação comunicativa, o que limita o desempenho de atividade linguística do usuário, já que em uma situação real de interação a expressão da língua não se limita a regulamentações descritivas (TRAVAGLIA,2009), mas o interlocutor atua na enunciação, como sujeito ativo e responsivo (BAKHTIN, 2009) sob a produção de efeitos de sentidos entre os interlocutores.

A segunda concepção, compreende a linguagem "como instrumento ("ferramenta") de comunicação" $(\mathrm{KOCH}, 2012$, p. 07), e reduz-se a sistematização da língua a um código, formulado através de regras, que se ajustam às formas fonéticas, gramaticais e lexicais da língua, que devem ser compreendidas pelos interlocutores. Assemelhando-se a primeira concepção, orienta um ensino de caráter normativo, na acepção dos princípios estruturalistas de Saussure e no transformacionalismo de Chomsky, segundo Travaglia (2009).

Diante disso, apontamos para a terceira concepção de linguagem, como forma ou processo de interação. Diferente da linguagem como expressão de pensamento ou como instrumento de comunicação, compreende que o indivíduo exterioriza seu pensamento a partir do contato com o interlocutor. Logo, a comunicação não se limita a demarcações padrões, mas considera a linguagem como um lugar de interação humana na qual a atividade linguística acontece na relação de troca de efeitos e sentidos, pois, segundo Geraldi (2012, p. 42), "é muito 
mais importante estudar as relações que se constituem entre os sujeitos no momento em que falam do que simplesmente estabelecer classificações e denominar tipos de sentenças". Essa concepção se insere no campo de uma linguística da enunciação, a qual, podemos entende-la a partir dessa reflexão:

\begin{abstract}
A língua constitui um processo de evolução ininterrupto, que se realiza através da interação verbal social dos locutores. [...] $\mathrm{O}$ diálogo, no sentido estrito do termo, não constitui, é claro, senão uma das formas, é verdade que das mais importantes, da interação verbal. Mas pode-se compreender a palavra "diálogo" num sentido amplo, isto é, não apenas como a comunicação em voz alta, de pessoas colocadas face a face, mas toda comunicação verbal, de qualquer tipo que seja. (BAKHTIN, 2009, p. 132; 127) (Grifos do autor)
\end{abstract}

Nessa perspectiva, estudar a língua é pontuar as relações que se estabelecem na interação comunicativa e não estabelecer descrições meramente gramaticais. Partindo disso, temos um ensino construído sob uma abordagem sociointeracionista, tendo em vista que os usuários da língua são sujeitos que vivem e se relacionam em sociedade, e, por consequência, carregados de ideologias, valores culturais e sócio históricos, que influenciam na língua e nas formas de comunicação humana. Além disso, essa concepção está fortemente ligada ao ensino de gramática reflexiva, a qual busca refletir sobre a língua e estudá-la com base em situações reais de interação.

Em termos de prática escolar, segundo Travaglia (2009), essa concepção está ligada ao ensino produtivo, o qual busca auxiliar o aluno a utilizar a língua com mais eficiência. Pois nesse ensino, divergente ao ensino normativo, o usuário não é compelido a se expressar conforme as normas padrões e vigentes, mas desenvolver seu desempenho linguístico para adequar a língua a diversas situações de comunicação, dado que existe uma gramática internalizada, que forma a competência linguística do falante, essa foi anteriormente constituída de uma série de conjuntos de regras que podem ser amadurecidos progressivamente, conforme a atividade linguística.

Analisando linguisticamente as três concepções retratadas, podemos averiguar que elas possuem visões distintas acerca das possibilidades de se conceber a linguagem, posto que a primeira concepção, afirma que o motivo pelo qual as pessoas estão impossibilitadas de efetuar a expressão clara deve-se ao fato 
de que não pensam, já que essa expressão se constrói no interior da mente, ou seja, é individual e não pode ser afetada pelo meio social. Já a segunda concepção, trata a linguagem como instrumento da interação, a qual o falante, que inserido em um meio social, acaba por transformar sua enunciação se adequando a realidade cotidiana (GERALDI, 2012; KOCH, 2012; SOARES, 1998; TRAVAGLIA, 2009).

Pondo em cheque as duas concepções, podemos considerar a linguagem como forma de processo de interação, como diz Bakhtin (2009, p. 127)

A verdadeira substância da linguagem não é constituída por um sistema abstrato de formas linguísticas nem pela enunciação monológica isolada, nem pelo ato psicofisiológico de sua produção, mas pelo fenômeno social da interação verbal, realizada pela enunciação ou pelas enunciações. A interação verbal constitui assim a realidade fundamental da língua.

Dessa forma, a linguagem é representada pela linguística da enunciação, sem restringi-la a um conjunto de regras, como é exposto na primeira corrente, e sem limitar a linguagem a função única e exclusiva estruturalista e pautada nas questões organizacionais da gramática. Nesse momento, a linguagem acontece no âmbito de produção de efeitos de sentido entre os interlocutores, que usufruem da língua como meio de interação e da forma que quiserem.

Além disso, essa maneira de olhar a linguagem, sustenta-se no objetivo de melhorar o desempenho do aluno e desenvolver nele, uma maior proficiência em práticas de oralidade, de leitura, escrita etc. Também possibilita ao falante, refletir sobre sua própria língua e sobre as situações com as quais interage no seu dia a dia e efetuar uma relação entre o que ele aprende na escola e o que é vivenciado no cotidiano, pois, percebemos há uma dicotomia entre o ensino da língua e o ensino da metalinguagem; a língua estudada com uma abordagem normativa resulta em um ensino caótico, no qual os alunos por vezes não possuem o domínio da variedade culta e são submetidos a análises de descrições gramaticais que contemplam hipóteses e regras que não fazem parte de um contexto real.

Na primeira abordagem, poucos exercícios verdadeiramente de língua são explorados, não abrangendo, portanto, o incentivo à livre produção textual, como ocorre na concepção sociointeracionista, dado que a construção textual é fundamental para expandir a competência comunicativa, que primordialmente seria o 
primeiro passo para possibilitar o aluno a compreender e analisar as descrições linguísticas com propriedade.

Nesse sentido, a terceira concepção de linguagem, fundamenta uma proposta sociointeracionista para o ensino, a qual, podemos considerar como a mais adequada para o ensino em sala de aula, posto que ela possibilita o contato do aluno com o texto, por meio da análise de situações de enunciação, uma vez que centraliza a linguagem num lugar no qual há possibilidade da constituição das mais diversas relações sociais, no qual os falantes se tornam sujeitos propriamente ditos, pois, concordando com Leite (2012) e Geraldi (2012), o ensino de língua também atua sobre o indivíduo no seu processo da formação de identidade, visto que nesse ambiente ele constrói experiências que norteiam seu aprendizado.

\section{FIGURAS DE LINGUAGEM E VÍCIOS DE LINGUAGEM: CONSIDERAÇÕES SOBRE A LÍNGUA PORTUGUESA EM UMA PERSPECTIVA FUNCIONALISTA}

A figura de linguagem é considerada um mecanismo de estilo utilizado no nosso idioma para tornar a mensagem mais expressiva e significativa e ainda, enfatizar ou embelezar a alguma construção. Nas gramáticas normativas e livros didáticos também é conhecida como figura de pensamento, figura de construção, figura de sintaxe, figura de estilo, figura retórica, no entanto, neste trabalho dissertaremos essa temática com a nomenclatura de figura de linguagem.

De acordo com o conceito encontrado no livro didático: "Gramática: Texto: Análise e Construção de Sentido", cuja autoria é conferida a Maria Luiza M. Abaurre, Maria Bernadete M. Abaurre, Marcela Pontara (2010), figuras de linguagem são recursos utilizados no nível dos sons, das palavras e também, das estruturas sintáticas. Desse modo, a figura de linguagem é utilizada para atribuir um efeito demarcado na interpretação do ouvinte ou leitor.

Os conceitos gramaticais de figura de linguagem e vício de linguagem estão pautados em aportes relacionados à abordagem normativa da gramática, em virtude de descrições que buscam adequá-los à normas a serem seguidas. Diferentemente do conceito empregado a figura de linguagem, como estilo para tornar a mensagem mais expressiva, o conceito aplicado ao vício de linguagem, por boa parte das gramáticas, é como recurso de expressões ou construções sintáticas que sofrem um desvio da norma padrão ou culta. Visão que envereda pra noção do 'errado'. 
Do mesmo modo, há fortes descrições e nomenclaturas, como segundo Bechara (2006), existem alguns tipos de vícios e anomalias de linguagem, dos quais são os seguintes: solecismo, barbarismo, estrangeirismo sintático e léxico e expressões idiomáticas. Outras gramáticas da Língua Portuguesa também consideram vício de linguagem, o hiato, cacofania, eco, colisão, ambiguidade e o pleonasmo, tema central da nossa análise. Também possui uma outra nomenclatura, o pleonasmo vicioso, segundo Abaurre; Abaurre; Pontara (2010).

Além disso, o conceito de vício de linguagem também se caracteriza por, "Incorreções e defeitos no uso da língua falada ou escrita. Originam-se do descaso ou do despreparo linguístico de quem se expressa" (CEGALLA, 2008, p. 634). Ou seja, ocorre quando há uma falta de atenção, ou pouco conhecimento a respeito das normas gramaticais pelos falantes. Esse fato confirma o caráter elitista ou aristocrático da gramática normativa, já que o critério da língua é baseado na classe prestígio ao uso das classes populares (TRAVAGLIA,2009).

Visto que, ao afirmar que o vício de linguagem ocorre quando há um desvio da norma, reforça a qualidade prescritiva da gramática normativa, já que as descrições são estabelecidas por especialistas com base no que seria consagrado pelos "bons escritores", o que exclui outras variedades de uso da língua a classificando como "desvios, erros, deformações ou degenerações" (TRAVAGLIA, 2009, p. 24). Enquanto a figura linguagem, comumente utilizada em textos literários, que carrega autoridade de gramáticos e escritores de prestígio, como Manual Bandeira, Olavo Billac, Machado de Assis, entre outros, é consagrada e considerada um meio de demarcação de estilística.

À vista disso, podemos refletir acerca desses conceitos, a partir de uma perspectiva funcionalista. O funcionalismo é uma abordagem linguística que estuda a relação entre a estrutura gramatical das línguas e os diferentes contextos comunicativos (CUNHA, 2013) a partir de análises e evidências empíricas. Em outras palavras, examina a língua em situações comunicativas, pois a concebe além da estrutura gramatical, uma vez que afirma que a língua reflete uma adaptação pelo falante a diferentes contextos comunicativos.

A análise funcionalista agrega a relação de linguagem e sociedade, o que a difere de outras correntes linguísticas, como o formalismo. O funcionalismo trabalha com enunciados retirados de contextos, que trazem relações interpessoais, evita frases prontas e descrições meramente normativas. A língua é investigada pelos 
fatores externos a sua estrutura linguística e permeada de elementos extralinguísticos, fora de padrões estáticos e homogêneos (CUNHA, 2013).

Portanto, ao pensarmos numa abordagem funcionalista, é possível considerar as descrições relativas à como os conceitos de figura de linguagem e vício de linguagem são ensinados pela abordagem normativa - a qual ocupa um lugar vigente no ensino de Língua Portuguesa - e como as concepções podem ser reconsideradas ao pensarmos no uso da figura de linguagem em contextos reais de interação e como os conceitos podem convergir a características semelhantes de vício de linguagem como instrumento expressivo.

Por esse ângulo, podemos analisar a maneira mais adequada a se ministrar o ensino da figura de linguagem e do vício de linguagem com outra roupagem, porém, não podemos negligenciar o ensino da norma culta, posto que, apesar de a mesma representar um aglomerado de regras preestabelecidas, também retrata todo um amontoado de conhecimentos acumulados historicamente constituindo um legado cultural a que todos os falantes de uma determinada sociedade precisam ter acesso e utilizar-se deles (GERALDI, 2012).

Dessa forma, ter o domínio sobre a gramática normativa evidencia um caráter de cunho político, pois a vivencia em sociedade é constituída por uma gama de diversidades nos âmbitos comunicativos e nas várias áreas de atuação do ser humano e, na maioria desses campos, para que haja a total integração e participação, requerem-se o domínio da habilidade e dominação completa das normas da língua padrão.

A problemática recai-se, então, na questão do ensino de gramática por um viés mecanicista, o qual é alheio às práticas discursivas de linguagem. Por conseguinte, é "o que, para que e como ensiná-la" (BRASIL,1998, p. 28). Por isso é de extrema relevância que o curso de Letras seja o meio pelo qual tenhamos uma preparação teórico-metodológica aos futuros professores de língua, de modo que eles suplantem o modelo de ensino padronizado da gramática normativa que "simula" a comunicação linguística. Só assim haverá uma mudança considerável na maneira que a gramática é ensinada nas escolas.

Diante disso, a vertente do funcionalismo, aliada a esses desejos de melhora no ensino da gramática, estuda a estrutura gramatical da língua inserida no contexto de comunicação por meio do qual ela foi usada. A linguagem é vista não mais apenas como um conjunto de regras e exemplos fora do meio real, mas sim 
enquanto instrumento de interação social. De acordo com Oliveira; Cezario (2007), os estudos funcionalistas lidam com a estrutura gramatical a partir das situações reais de comunicação, considerando a interação, os participantes e o contexto discursivo. Com isso, essa vertente amplia seu olhar sobre a gramática, constituindo-se um eficaz aparato teórico a mais para o professor de Língua Portuguesa para o trabalho em sala de aula.

Tendo em vista o manuseio das situações de uso reais em sala de aula, os vícios de linguagem, se mostrados aos alunos como marcas da oralidade e não como um erro ou meramente desnecessários, trarão uma perspectiva mais interpessoal, de proximidade, já que são expressões muito usuais por parte dos falantes. Assim, como uma maior compreensão do significado e do porquê são utilizados, de que forma e de que maneira podemos aceitá-los como parte integrante na nossa linguagem funcional.

E para que seja efetuado esse ensino e aprendizagem da figura de linguagem, vale ressaltar, a importância da relação professor-aluno, que dinamiza e dá sentido ao trabalho educativo, visto que essa relação deve ser baseada na confiança e no respeito mútuo. A relação interpessoal de professor e aluno se torna mais fluida se os dois possuírem essa proximidade, pois, somente assim, o ensino se torna mais informal e mais prazeroso para ambos.

No âmbito da Língua Portuguesa, a abordagem do conteúdo de figura de linguagem, continua sendo de cunho prescritivo, que consiste em levar o aluno a substituir seus próprios padrões de exercício linguístico, que são julgados pela gramática normativa errados/inaceitáveis ou desnecessários por padrões considerados corretos. É, portanto, um ensino que comete interferências nas habilidades linguísticas existentes em cada falante, além disso, o ensino prescritivo somente atende aos objetivos do ensino de língua materna.

Lamentavelmente, esse ensino é o mais hipervalorizado e praticado nas escolas no ensino de Língua Portuguesa, posto que ele esteja ligado à gramática normativa e privilegia a variedade da norma culta, tendo como seu objetivo base, guiar o aluno a dominar a norma culta e a correção formal da linguagem. Para Lima (2017, p. 103): 
para o 'bom uso' da língua, como se esta fosse um jogo de regras e estratégias que se enquadram em um molde fechado e linear. Dentro desse paradigma, o ensino organiza-se em torno do método mnemônico, proposto pelos manuais, baseado apenas em exercícios de análise e classificação de termos e regras prontas, previstas pelo modelo da gramática normativa. Essa visão, no mínimo reducionista, inviabiliza possibilidades de enxergar os contextos reais de produção dos enunciados, os quais se configuram como lugares de uso concreto da língua e onde os sentidos do mundo são construídos e reconstruídos por meio da linguagem, valorizando-se, por exemplo, competências linguísticas da leitura e da oralidade.

Assim sendo, causa prejuízos na formação linguística do aluno e um retrocesso em sua competência comunicativa, que se torna limitada. Além do que, esse ensino não tem tido êxito, pois não consegue alcançar seu objetivo principal, que é o uso satisfatório da norma culta.

Nessa multiplicidade de abordagens, aponta-se para o ensino produtivo, baseado na abordagem funcionalista, que tem por objetivo ensinar novas habilidades ao falante, tornando o uso da língua mais eficiente e sem alterar os "padrões", os conhecimentos, que o aluno já adquiriu, mas sim ampliar seus recursos e auxiliá-lo, a saber, usar esses recursos, em diferentes situações e em suas variadas potencialidades. Logo, o ensino produtivo é, sem dúvida, o mais eficaz e adequado o ensino de língua materna, posto que ele implica no desenvolvimento da competência comunicativa e na aquisição de novas habilidades, se utilizando de usos reais da língua.

\section{O CASO DO PLEONASMO: ILUSTRAÇÕES A PARTIR DE CONTEXTOS DE USO COM PROPOSTAS DE ALICAÇÃO NO ENSINO DE LÍNGUA PORTUGUESA SOB UMA ABORDAGEM INTERACIONISTA}

Do latim pleonasmus, o termo "pleonasmo" é caracterizado como uma figura de linguagem que significa superabundância, ou seja, um recurso linguístico usado para reforçar uma ideia mencionada, seja intencional ou não. "É a repetição de um termo já expresso ou de uma ideia já sugerida, para fins de clareza ou ênfase" (BECHARA, 2006, p. 594).

Nos termos de Said Ali, linguista em quem Evanildo Bechara (1969) se apoia, o pleonasmo "consiste em repetir um termo de uma frase empregando outra 
expressão de sentido equivalente" (ALI, 1964, p. 299), no entanto, analisa-lo, pressupõe certos cuidados, pois, se

Empregado por descuido e sem necessidade alguma, o pleonasmo é um vício de linguagem, conhecido mais particularmente pelos nomes de tautologia e redundância. Mas o pleonasmo também se usa como figura de sintaxe, servindo para reforçar a ideia e expressá-la com mais clareza. (ALI, 1964, p. 299)

O pleonasmo como funções expressivas e com objetivo intencional, é geralmente relacionado ao pleonasmo literário, que dispõe de uma função poética, para atribuir maior expressividade ao discurso. Essa função é geralmente associada ao pleonasmo como figura de linguagem, e não como vício de linguagem, por ela ser utilizada pelos autores renomados como, por exemplo, por Alberto de Oliveira (1959, p. 68) apud Brasileiro (2015, p. 146) no seguinte verso do poema "lam vinte anos..."

"lam vinte anos desde aquele dia

Quando com os olhos eu quis ver de perto

Quando em visão com os da saudade via"

O pleonasmo literário encontra-se no segundo verso, no qual é empregado o verbo ver e posto também, o órgão responsável por esse sentido, os olhos, nisso conferindo redundância, uma vez que para ver, deve-se impreterivelmente utilizar da visão. Vale ressaltar que, o autor utiliza desse recurso com o fim de enfatizar a expressão, na qual ele guarda o momento de maneira tal que the foi necessário repetir a ideia transpassada para embelezar a construção poética. Portanto, considerada intencional, a gramática considera casos desse tipo como pleonasmo literário, uma figura de estilo.

Segundo Castilho (1988) apud Travaglia (2009, p. 25) a gramática prescritiva sustenta-se em argumentos "elitistas ou aristocráticos", com "um forte sentimento de estratificação social, e, sobretudo, de 'diferença social'", tendo em vista que as normas de boa utilização da língua são baseadas nos escritores consagrados, a valorização da escrita se sobrepõe a língua oral. Portanto, o ensino prescritivo carrega esse caráter aristocrático, e é possível ver essa distinção no exemplo anteriormente citado, que, a poesia escrita por Oliveira (1959) é considerada pela gramática como pleonasmo literário e não vício de linguagem, puramente devido ao caráter de autoridade cultural. 
No entanto, no Quadro 01, abaixo, podemos listar uma extensa lista de exemplos e refletir acerca da distinção feita entre o pleonasmo vicioso e o pleonasmo literário e como eles podem convergir no ensino de Língua Portuguesa:

Quadro 01: Exemplos de pleonasmos viciosos

\begin{tabular}{|c|c|c|}
\hline \multicolumn{3}{|c|}{ PLEONASMOS VICIOSOS } \\
\hline Hemorragia de sangue & Duas metades & Ambos os dois \\
\hline Sair para fora & Retornar de novo & Adiar para depois \\
\hline Entrar para dentro & Encarar de frente & Subir para cima \\
\hline Certeza absoluta & Conclusão final & Antecipar para antes \\
\hline Últimos acabamentos & Acabamento final & Panorama geral \\
\hline Fato verídico & Outra alternativa & Consenso geral \\
\hline Elo de ligação & Regra geral & Agora já \\
\hline Escolha opcional & Verdade verdadeira & Propriedade característica \\
\hline Monopólio exclusivo & Fato real & Seguir em frente \\
\hline Protagonista principal & Verdade verdadeira & Sentidos pêsames \\
\hline Na minha opinião pessoal & Sorriso nos lábios & Há muitos anos atrás \\
\hline Si mesmo & Juntamente com & Repetir de novo \\
\hline Duas metades iguais & Junto com & Habitat natural \\
\hline Dupla de dois & Já não há mais & Todos foram unânimes \\
\hline Baseado em fatos reais & Novidade inédita & $\begin{array}{l}\text { Comparecer } \\
\text { pessoalmente }\end{array}$ \\
\hline Ver com os próprios olhos & Voltar atrás & Planejar antecipadamente \\
\hline Viver a vida & Preparar de antemão & Inaugurar novo \\
\hline Introduzir dentro & Arder em chamas & Sonhar um sonho \\
\hline Retornar de novo & Pisar com os pés & Gritar alto \\
\hline Anexar junto & Decapitar a cabeça & Manter o mesmo \\
\hline Prever antecipadamente & Surpresa inesperada & Pequenos detalhes \\
\hline Labaredas de fogo & Surdo do ouvido & Empréstimo temporário \\
\hline Maluco da cabeça & Hemorragia de sangue & Um mês de mensalidade \\
\hline Pessoa humana & Sintomas indicativos & Um ano de anuidade \\
\hline Abertura inaugural & Viúva do falecido & Cego dos olhos \\
\hline Hepatite do fígado & Demente mental & Prevenir antes \\
\hline Última versão definitiva & Limite extremo & Nova criação \\
\hline Planos para o futuro & A seu critério pessoal & Conviver junto \\
\hline Eu digo-te isto a ti & De sua livre escolha & Canja de galinha \\
\hline Brisa matinal da manhã & Estrelas do céu & Própria autobiografia \\
\hline Continuar ainda & Infarto do coração & Bonita caligrafia \\
\hline Amanhecer o dia & Preferir mais & Abusar demais \\
\hline Preconceito intolerante & Multidão de pessoas & Suicidou a si mesmo \\
\hline Goteira no teto & Países do mundo & De chapéu na cabeça \\
\hline Caiu uma queda & Dar de graça & Ganhar grátis \\
\hline
\end{tabular}


Fonte: Elaborado pelos autores (2018), a partir da coleta em livros didáticos e em sites sobre figura de linguagem, particularmente, deste site: $<$ https://www.normaculta.com.br/lista-dos-pleonasmosmais-comuns/ >. Acesso em: 20 mai. 2018.

Ao analisarmos os exemplos desse quadro, podemos observar que 0 pleonasmo vicioso vai ao encontro do conceito de pleonasmo literário, visto que, por exemplo, em "Fato real" comumente utilizado na língua oral - a qual é o parâmetro para medir, segundo a abordagem prescritiva, erros que fogem da norma culta - o falante a utiliza presumivelmente para fixar a ideia de veracidade de um acontecimento ou registro, e, por conta disso, repete a mesma expressão, tal como o em "verdade verdadeira", possivelmente com intuito de enfatizar.

No entanto, o ensino escolar, baseado na gramática normativa, classifica o pleonasmo como figura de linguagem, quando é chamado de pleonasmo literário, aquele que repete a ideia intencionalmente para produzir efeito de estilo, enquanto o pleonasmo vicioso é considerado ocorrem repetições excessivas, de termos ou frases, ferindo, de certo modo, o estilo desejado pelos moldes da gramática normativa, embora apresente características intencionais do falante de demarcar a expressão por meio da repetição. O que difere nesse caso, é o lugar social de enunciação, pois quando proferido por autores consagrados, consideramos pleonasmo literário; do contrário, por pessoas comuns, cai no 'erro', no desvio à norma, daí, denominarmos de pleonasmo vicioso.

Diante disso, ao nos atentarmos no ensino de Língua Portuguesa dispondose de uma perspectiva interacionista é possível ensinar a língua nos retendo dessas distinções de "certo e errado", impostas pela máxima da gramática normativa, de forma que o educando não necessite pensar a língua de uma maneira utópica, mas considerando que seu dialeto em contexto real não representa 'erro', mas, pode ser considerado inclusive, uma marca de sua oralidade.

Nessa abordagem interacionista e construtivista de ensino, a participação do sujeito no processo de construção do conhecimento é fundamental, de acordo com Koll (2009, p. 19), o

[...] ensino parte do fato óbvio de que a escola torna acessíveis ao seus alunos aspectos da cultura que são fundamentais para seu desenvolvimento pessoal, e não só no âmbito cognitivo; a educação é motor para o desenvolvimento, considerado globalmente, e isso também supõe incluir as capacidades de equilíbrio pessoal, de inserção social, de relação interpessoal e motoras. Ela também parte 
de um consenso já bastante arraigado em relação ao caráter ativo da aprendizagem, o que leva a aceitar que está é fruto de uma construção pessoal, mas na qual não intervém apenas o sujeito que aprende; os "outros" significativos, os agentes culturais, são peças imprescindíveis para essa construção pessoal, para esse desenvolvimento ao qual aludimos

Em outras palavras, o ensino é desenvolvido pelo educador e o educando por meio de formação que vise a interligação da aprendizagem com contextos significativos no meio social. No entanto, diferindo da teoria, o que percebemos no contexto escolar, é que ela ainda se encontra antiquado, já que não dispõe dessa correlação entre linguagem, interação e cognição, pondo, por vezes,

[... um ensino e aprendizagem dissociado dos processos interacionais e de estratégias cognitivas que favoreçam a ampliação de conhecimentos dos alunos, a título de exemplo, práticas de leitura decodificadas sem espaço para que o aluno possa interagir com o texto, ou fazer uma relação com seu dia a dia em detrimento da relação língua com o social. (ALVES, 2009, p. 2198)

Em virtude disso, se pegarmos como exemplo a oração, "Vi com meus próprios olhos", muito frequente quando queremos que acreditem no que estamos descrevendo, ao invés de descartá-la ou limitá-la a uma repetição supérflua, ou vício de linguagem, de um termo ou de um sentido empregado por uma palavra já mencionada, podemos expor aos alunos tamanha importância de compreendermos o porquê de a mesma ser utilizada, que tem por função chamar a atenção de quem está ouvindo ou lendo, para que o interlocutor saiba que o que foi dito não é mera falácia, mas uma verdade presenciada.

Por isso, o ensino interacionista é o mais adequado a ser utilizado nas escolas. A esse respeito, Matêncio (2001, p. 78) destaca que:

Uma interação verbal é, ao mesmo tempo, um evento de comunicação - de construção de sentidos - e de construção de relações sociais, o que explica por que um evento de interação é o ponto de articulação entre o sujeito e o social, em outras palavras, o lugar de (re) construção da realidade subjetiva e social.

Ou seja, é imprescindível que o aluno esteja em constante interação com seu meio social e que relacione ele em seu meio escolar. Neste contexto, torna-se evidente a necessidade de formarmos profissionais da língua, capazes de utilizarem 
estratégias interativas de ensino de língua materna que favoreçam o desenvolvimento da capacidade cognitiva do aprendiz, em qualquer grau de escolaridade. E, no caso, no ensino do pleonasmo, como figura de linguagem, vício de linguagem e suas implicações com seus usos efetivos no cotidiano.

\section{CONSIDERAÇÕES FINAIS}

Este estudo discutiu acerca do tratamento dado ao ensino do pleonasmo na escola, com foco no modo como são classificadas/identificadas as figuras de linguagem e os vícios de linguagem no ensino de Língua Portuguesa. Neste aspecto, aprofundou-se o olhar para a questão da gramática, que, ao longo dos anos, tem prevalecido nos contextos escolares, imprimindo um caráter normativo e dogmático sobre os usos da língua. Para averiguar esse ponto, partimos das concepções da linguagem, refletindo como cada uma delas, tem contribuído para a construção de um ensino tradicional nas escolas, em detrimento do ensino produtivo, o qual valida a eficácia ao ensino de língua materna.

Diante desse cenário, aponta-se para a necessidade de um ensino baseado em abordagens interacionistas, as quais favorecem o desenvolvimento de habilidades linguísticas que resultam na eficácia da competência comunicativa. Tendo em conta especialmente, o ensino da figura de linguagem e vício de linguagem e como seus conceitos se convergem na gramática prescritiva, visto que o vício de linguagem, em última análise, propõe o mesmo sentido da figura de linguagem, no entanto, é dissociado dado que é comumente utilizado na oralidade, tal como ocorre com o pleonasmo.

À vista disso, é relevante a análise da concepção normativa que orienta o ensino do pleonasmo, ainda muito presente na prática docente, que, por vezes, limita o aluno a uma compreensão simbólica negativa do pleonasmo como vício e não como figura de linguagem, com caráter estilístico de ênfase por estar associado à oralidade. Em face disso, propomos a adequação do ensino a uma concepção interacionista, com fim de reconsiderar conceitos que foram consolidados.

Assim, é relevante repensarmos o ensino da língua, para que possamos examinar se conceitos referentes ao pleonasmo são realmente suficientes para o estudo desse recurso. É urgente então, uma maneira distinta de olhar a língua para 
sustentar o objetivo de melhorar o desempenho do aluno, e com isso, desenvolver uma maior proficiência em práticas de oralidade, de leitura e de escrita.

\section{REFERÊNCIAS}

ABAURRE, Maria Luiza M.; ABAURRE, Maria Bernadete M.; PONTARA, Marcela. Gramática: texto - análise e construção de sentido. São Paulo: Moderna, 2010.

ANTUNES, Irandé. Aula de Português: encontro e interação. São Paulo: Parábola, 2003.

Muito além da gramática: por um ensino de línguas sem pedras no caminho. São Paulo: Parábola, 2007.

ALI, M. S. Gramática Histórica da Língua Portuguesa. 3. ed. Brasília: Editora da Universidade de Brasília, 1964.

ALVES, Maria de Fátima. Interação em aulas de Língua Portuguesa e desenvolvimento cognitivo do aluno. In: VI Congresso Internacional da ABRALIN. Anais... João Pessoa: Idéia, 2009. p. 2198-2207. Disponível em: < http://www.leffa.pro.br/tela4/Textos/Textos/Anais/ABRALIN 2009/PDF/Maria\%20de \%20F\%C3\%A1tima\%20Alves\%20-\%20ok.pdf >. Acesso em: 22 mai. 2018.

AZEREDO, J. C. Gramática Houaiss da língua portuguesa. 2. ed. São Paulo: Publifolha, 2008.

BAGNO, M. Gramática de bolso do português brasileiro. São Paulo: Parábola, 2013.

. Gramática pedagógica do português brasileiro. São Paulo: Parábola,

Nada na língua é por acaso. São Paulo: Parábola, 2007.

BAKHTIN, Mikhail (VOLOCHINOV, Valentin Nikolaevich). Marxismo e filosofia da linguagem. Tradução Michel Lahud e Yara Frateschi Vieira. 13. ed. São Paulo: Hucitec, 2009.

BECHARA, Evanildo. A contribuição de M. Said Ali à Linguística Portuguesa. Porto Alegre: Instituto Cultural Brasileiro-Árabe, 1969.

Moderna gramática portuguesa. 37.ed. revista e ampliada. Rio de Janeiro: Nova Fronteira, 2006.

BRASIL. Secretaria de Educação Fundamental. Parâmetros Curriculares Nacionais: terceiro e quarto ciclos do Ensino Fundamental: Língua Portuguesa / Secretaria da Educação Fundamental. Brasília: MEC/SEF, 1998. 
BRASILEIRO, Ada Magaly M. Leitura e produção textual. Porto Alegre: Penso, 2015.

BRITTO, L.P.L. A sombra do caos: ensino de língua $X$ tradição gramatical. Campinas: ALB, 1997.

CASTILHO, A. T. de. Nova gramática do português brasileiro. São Paulo: Contexto, 2010.

; ELIAS, V. M. Pequena gramática do português brasileiro. São Paulo: Contexto, 2012.

CEGALLA, D. P. Novíssima gramática da língua portuguesa. 48.ed. revisada. São Paulo: Companhia Editora Nacional, 2008.

CUNHA, Angélica Furtado da. Funcionalismo. In: MARTELOTTA, Mário Eduardo (Org.). Manual de linguística. 2. ed. São Paulo: Contexto, 2013. p. 157-176.

FARACO, Carlos Alberto. Ensinar X não ensinar gramática: ainda cabe esta questão?. Calidoscópio, São Leopoldo (RS), Vol. 4, n. 1, p. 15-26, jan/abr 2006. Disponível em: < http://moodle.stoa.usp.br/file.php/1103/textos/Norma e Ensino/FARACO EnsinarGr amatica.pdf >. Acesso em: 23 mai. 2018.

FRANCHI, Carlos et al. Mas o que é mesmo 'gramática'? São Paulo: Parábola, 2006.

FARIAS, Washington Silva de. As gramáticas dos linguistas no Brasil: efeitos de sentido polêmicos sobre a língua a re-conhecer. Linguagem em (Dis)curso LemD, Tubarão, SC, v. 14, n. 1, p. 105-122, jan./abr. 2014.

FERRAREZI JR, C. F. da; TELES, I. M. Gramática do brasileiro: uma nova maneira de entender a língua. São Paulo: Globo, 2008.

GERALDI, João Wanderley. Concepções de linguagem e ensino de português. In: GERALDI, João Wanderley. $\mathbf{O}$ texto em sala de aula. 5. ed. São Paulo: Ática, 2012, p. 39-46. [1985].

$\mathrm{KOCH}$, Ingedore Villaça. A inter-ação pela linguagem. 11. ed. São Paulo: Contexto, 2012.

KOLL, C. O construtivismo na sala de aula. 6. ed. São Paulo: Ática, 2009.

LIMA, Francisco Renato. Uma reunião teórica entre língua, linguagem e linguística: entrelaçando olhares para a formação do professor e o ensino de Língua Portuguesa. Miguilim - Revista Eletrônica do Netlli, Crato, v. 6, n. 3, p. 91-112, set.-dez. 2017. 
. Tendências pedagógicas, opção político-ideológica e concepções de

linguagem: das correlações, tomadas de partido e aproximações didáticometodológica no ensino de Língua Portuguesa. [Comunicação oral]. In: II Congresso Nacional de Variação/Diversidade Linguística e Letramentos (II CONVALLE), Universidade Federal do Piauí, 4 a 6 de setembro de 2018. p. 01-04.

LEITE, Lígia Chiappini de Moraes. Gramática e Literatura: desencontros e esperanças. In: GERALDI, João Wanderley. 0 texto em sala de aula. 5. ed. São Paulo: Ática, 2012, p. 17-25.

LUFT, Celso Pedro. Língua e liberdade: por uma nova concepção da língua materna. 8. ed. São Paulo: Ática, 2008.

MARTELOTTA, Mário Eduardo. Conceitos de gramática. In: MARTELOTTA, Mário Eduardo (Org.). Manual de linguística. 2. ed. São Paulo: Contexto, 2013. p. 43-70.

MATÊNCIO, M. L Estudo da língua falada e aula de língua materna. São Paulo: Mercado de Letras, 2001.

NEVES, M. H. de Moura. Gramática na Escola. 8. ed. São Paulo: Contexto, 2010. . Gramática de usos do português. São Paulo: Editora da UNESP, 2000. A gramática do português revelada em textos. São Paulo: Editora da UNESP, 2018.

OLIVEIRA, Mariangela Rios de; CEZARIO, Maria Maura. PCN à luz do funcionalismo linguístico, Linguagem \& Ensino, v. 10, n.1, p. 87-108, jan.-jun. 2007.

PERINI, M. A. Gramática do português brasileiro. São Paulo: Parábola, 2010.

POSSENTI, Sírio. Por que (não) ensinar gramática na escola. 11. ed. Campinas: ALB/Mercado de Letras, 1996.

SOARES, Magda. Concepções de linguagem e o ensino da Língua Portuguesa. In: BASTOS, N. B. Língua Portuguesa, perspectiva, ensino. São Paulo: PUC/SP, 1998. p. $53-60$.

TRAVAGLIA, Luiz Carlos. Gramática e interação: uma proposta para o ensino de gramática. 14. ed. São Paulo: Cortez, 2009. [1995]. 